\title{
Reticulocyte to Erythrocyte Ratio
}

National Cancer Institute

\section{Source}

National Cancer Institute. Reticulocyte to Erythrocyte Ratio. NCI Thesaurus. Code C64828.

The determination of the ratio of reticulocytes compared to erythrocytes in a blood sample. The measurement may be expressed as a ratio or percentage. 